\title{
Identification of human liver cytochrome P450 isoforms mediating omeprazole metabolism
}

\author{
TOMMY ANDERSSON ${ }^{1,2}$, JOHN O. MINERS ${ }^{2}$, MAURICE E. VERONESE ${ }^{2}$, WICHITTRA TASSANEEYAKUL ${ }^{2}$, \\ WONGWIWAT TASSANEEYAKUL ${ }^{2}$, URS A. MEYER ${ }^{3}$ \& DONALD J. BIRKETT ${ }^{2}$ \\ ${ }^{1}$ Clinical Pharmacology, Astra Hässle AB, S-43183 Mölndal, Sweden, ${ }^{2}$ Department of Clinical Pharmacology, Flinders \\ University of South Australia, Bedford Park, SA 5042, Australia and ${ }^{3}$ Department of Pharmacology, Biocenter of the \\ University of Basel, CH-4056 Basel, Switzerland
}

1 The in vitro metabolism of omeprazole was studied in human liver microsomes in order to define the metabolic pathways and identify the cytochrome P450 (CYP) isoforms responsible for the formation of the major omeprazole metabolites.

2 The four major metabolites identified in vitro, in tentative order of importance, were hydroxyomeprazole, omeprazole sulphone, 5-O-desmethylomeprazole, and an unidentified compound termed metabolite $X$. Omeprazole pyridone was also detected but could not be quantitated. Incubation of hydroxyomeprazole and omeprazole sulphone with human microsomes resulted in both cases in formation of the hydroxysulphone. The kinetics of formation of the four primary metabolites studied were biphasic suggesting the involvement of multiple CYP isoforms in each case. Further studies used substrate concentrations at which the high affinity activities predominated.

3 Formation of the major metabolite, hydroxyomeprazole, was significantly correlated with S-mephenytoin hydroxylase and with benzo[a]pyrene metabolism and CYP3A content. Inhibition studies with isoform selective inhibitors also indicated a dominant role of S-mephenytoin hydroxylase with some CYP3A contribution in the formation of hydroxyomeprazole. Correlation and inhibition data for the sulphone and metabolite $\mathrm{X}$ were consistent with a predominant role of the CYP3A subfamily in formation of these metabolites. Formation of 5-O-desmethylomeprazole was inhibited by both $\mathrm{R}$, $\mathrm{S}$-mephenytoin and quinidine, indicating that both S-mephenytoin hydroxylase and CYP2D6 may mediate this reaction in human liver microsomes and in vivo.

4 The $V_{\max } / K_{m}$ (indicator of intrinsic clearance in vivo) for hydroxyomeprazole was four times greater than that for omeprazole sulphone. Consistent with findings in vivo, the results predict that omeprazole clearance in vivo would be reduced in poor metabolisers of mephenytoin due to reduction in the dominant partial metabolic clearance to hydroxyomeprazole.

Keywords omeprazole human microsomal metabolism kinetics CYP isoforms

\section{Introduction}

Omeprazole is a substituted benzimidazole that interacts with the gastric proton pump $\mathrm{H}^{+}, \mathrm{K}^{+}$-ATPase in the secretory membrane resulting in a potent long-acting inhibition of gastric acid secretion [1-3]. Due to this effective control of gastric acid secretion the healing rate of acid related diseases (i.e. peptic ulcers and reflux oesophagitis) obtained with omeprazole is more rapid than that observed for histamine $\mathrm{H}_{2}$-receptor blockers [4-6].
Approximately half of an oral dose of omeprazole is systemically available as a result of a substantial firstpass elimination by the liver [7]. Plasma elimination half-life of omeprazole ranges between 0.5 and $1 \mathrm{~h}$ and total plasma clearance is about $600 \mathrm{ml} \mathrm{min} \mathrm{mi}^{-1}$ [7]. Omeprazole is extensively metabolised by the liver and the major metabolites found in plasma are hydroxyomeprazole and omeprazole sulphone [7] neither of which contributes to the pharmacodynamic effect 
(B. Wallmark, personal communication). Following both intravenous and oral administration $80 \%$ of a given dose is excreted as metabolites in urine and the residual amount is found in faeces, primarily originating from biliary secretion $[8,9]$. The major metabolites found in urine were hydroxyomeprazole and its corresponding carboxylic acid [10]. Neither omeprazole nor omeprazole sulphone were detected in significant amounts in urine indicating that the sulphone is completely further metabolised to secondary metabolites. Earlier studies have shown that a few $(<5 \%)$ individuals metabolise omeprazole at a significantly slower rate, with half-lives of 1.5-3 h, and the metabolism of omeprazole, particularly the formation of hydroxyomeprazole, has been shown to cosegregate with the 4-hydroxylation of S-mephenytoin [11-15]. S-mephenytoin 4-hydroxylation is catalysed by a CYP2C isoform (possibly CYP2C18) and this isoform is polymorphically expressed with $\sim 3 \%$ of the Caucasian population being slow metabolisers.

So far the metabolism of omeprazole in humans has only been studied in vivo and no in vitro experiments in human liver microsomes have been reported.

This report presents the results of studies on the formation kinetics of omeprazole metabolites with human liver microsomes. Also, the CYP isoforms in human liver responsible for formation of the various metabolites of omeprazole were investigated by correlation studies with isoform selective activities previously determined in a range of livers, and by the effects of chemical inhibitors selective for various CYP isoforms.

\section{Methods}

\section{Chemicals}

Omeprazole (5-methoxy-2[[(4-methoxy-3,5-dimethyl2-pyridinyl)-methyl]sulphinyl]-1H-benzimidazole)

(Figure 1),

Omeprazole sulphone (5-methoxy-2-[[(4-methoxy-3, 5-dimethyl-2-pyridinyl)methyl]sulphonyl]-1Hbenzimidazole) (Figure 1),

Hydroxyomeprazole (5-methoxy-2-[[(4-methoxy-3methyl-5-hydroxymethyl-2-pyridinyl)-methyl]sulphinyl]1H-benzimidazole) (Figure 1),

H 215/02 or 5-O-desmethylomeprazole (5-hydroxy-2[[(4-methoxy-3,5-dimethyl-2-pyridinyl)-methyl] sulphinyl]-1H-benzimidazole) (Figure 1),

H 168/22 or omeprazole sulphide (5-methoxy-2-[[(4methoxy-3,5-dimethyl-2-pyridinyl)methyl]thio]-1Hbenzimidazole)

H 153/95 or omeprazole pyridone (5-methoxy-2-[[(4hydroxy-3,5-dimethyl-2-pyridinyl)methyl]thio]-1Hbenzimidazole)

Footnote: For information on cytochrome P450 nomenclature, see Nebert et al. DNA 1993; 12: $1-51$
H 195/77 or hydroxysulphone (5-methoxy-2-[[(4methoxy-3-methyl-5-hydroxymethyl-2-pyridinyl) methyl]sulphonyl]-1H-benzimidazole) (Figure 1),

H 195/69 or hydroxyomeprazole-sulphide (5-methoxy2-[[(4-methoxy-3-methyl-5-hydroxymethyl-2-pyridinyl)methyl]thio]-1H-benzimidazole)

H 182/68 or 5-O-desmethylomeprazole-sulphide (5hydroxy-2-[[(4-methoxy-3,5-dimethyl-2-pyridinyl) methyl] thio]-1H-benzimidazole)

Internal standard (4,6-dimethyl-2-[[(4-methoxy-2pyridinyl)methyl]sulphinyl]-1H-benzimidazole)

These chemicals were obtained from Astra Hässle $A B$ (Mölndal, Sweden). Coumarin, diethyldithiocarbamate and troleandomycin were purchased from Sigma Chemical Co (St Louis, MO). Other drugs were obtained from the following sources: $\alpha$-naphthoflavone from Aldrich Chemical Co (Milwaukee, WI), sulphaphenazole from Ciba-Geigy Aust (Sydney, Australia), R, Smephenytoin from Sandoz Ltd (Basel, Switzerland) and quinidine from Burroughs Wellcome Aust (Sydney, Australia). Furafylline was a kind gift from Dr Rodolpho Gasser, Hoffmann La Roche (Basel, Switzerland).

$\mathrm{NADP}^{+}$, glucose 6-phosphate and glucose 6-phosphate dehydrogenase were purchased from Sigma Chemical Co (St Louis, MO). All other reagents and solvents were of analytical grade.

\section{Liver samples}

Human liver samples were obtained from renal transplant donors, relevant details of the donors of livers used in the present study (KDL 4, 5, 7, 9-11, 13, 17, 20, 21, 24, 26, 27, 35 and H5-15, 17-23) have been published elsewhere $[16,17]$. Liver samples were stored at $-80^{\circ} \mathrm{C}$ until used. Microsomes were prepared by differential centrifugation as previously described [18] and microsomal protein concentration was measured by the procedure of Lowry et al. [19] using crystalline bovine serum albumin as standard. Ethical approval was obtained to use these livers for drug metabolism studies.

\section{Measurement of omeprazole metabolites in human liver microsomes}

The method used for determination of omeprazole sulphone and hydroxyomeprazole along with two other minor metabolites concentrations in microsomal incubations have been described in detail elsewhere [20]. Briefly, reaction mixtures contained human liver microsomal protein $(1 \mathrm{mg})$, omeprazole $(2.5-500 \mu \mathrm{M})$ and NADPHgenerating system (consisting of $1 \mathrm{~mm} \mathrm{NADP}{ }^{+}, 10 \mathrm{~mm}$ glucose 6-phosphate, 2 units glucose 6-phosphate dehydrogenase, and $5 \mathrm{mM} \mathrm{MgCl}_{2}$ ) in a final volume of $1.0 \mathrm{ml} 0.1 \mathrm{M}$ potassium dihydrogen phosphate buffer ( $\mathrm{pH}$ 7.4). Samples were incubated at $37^{\circ} \mathrm{C}$ for $15 \mathrm{~min}$ and then extracted with dichloromethane:butanol (99:1). The organic phase was evaporated to dryness under nitrogen, and the residue was reconstituted in the h.p.l.c. 
<smiles>CCc1ncc(C)c(OC)c1C</smiles>

IV<smiles>CS(=O)(=O)c1nc2cc(O)ccc2[nH]1</smiles>
Metabolite X<smiles>COc1ccc2c(c1)N=C(S(=O)Cc1ncc(C(=O)O)c(OC)c1C)NC2</smiles>

Figure 1 Proposed scheme for omeprazole metabolism in humans. Structures: I $=$ omeprazole, II $=$ hydroxyomeprazole, III $=$ omeprazole sulphone, IV = 5-O-desmethylomeprazole $(\mathrm{H} 215 / 02), \mathrm{V}=$ hydroxysulphone $(\mathrm{H} 195 / 77)$, and VI = carboxyomeprazole (H 193/48) [S-MPH = S-mephenytoin hydroxylase].

mobile phase (dichloromethane:5\% $\mathrm{NH}_{4} \mathrm{OH} / \mathrm{MeOH}: 2-$ propanol (191:8:1) at a flow rate of $\left.1.5 \mathrm{ml} \mathrm{min}^{-1}\right)$. Using a Superspher SI-60 column ( $4 \mu \mathrm{M}$ particle size, $125 \times 4$ $\mathrm{mm}$; E. Merck, Darmstadt, Germany) and an Aquapore Silica guard column $(7 \mu \mathrm{M}$ particle size, $15 \times 3 \mathrm{~mm}$, Brownlee Laboratories, CA) retention times for omeprazole sulphone, omeprazole, hydroxyomeprazole and internal standard (see chemicals) were 2.0, 2.5, 13.5 and $3.3 \mathrm{~min}$ respectively. Two minor metabolites, 5-Odesmethylomeprazole (H 215/02) and an unknown compound (termed metabolite $\mathrm{X}$ ), eluted at $11 \mathrm{~min}$ and $3.8 \mathrm{~min}$, respectively. Omeprazole sulphide, which eluted at $1.3 \mathrm{~min}$, was formed also in the samples with no NADPH-generating system, indicating that a chemical transformation during the preparation procedures resulted in this peak. In addition, since omeprazole pyridone (retention time $16 \mathrm{~min}$ ) was formed in very small amounts only, as indicated by the size of the peak, this metabolite was not further evaluated. Hydroxysulphone (H 195/77) was eluted at 9 min following injection of a synthetic standard of this compound.

\section{Kinetics of omeprazole metabolism}

Eleven different concentrations of omeprazole, ranging from 2.5 to $500 \mu \mathrm{M}$, were used in the kinetic experiments. Four different livers (H8, H9, H10 and H15) were studied and apparent $K_{m}$ and $V_{\max }$ values for the formation of omeprazole sulphone and hydroxyomeprazole were determined. The Michaelis-Menten parameters were initially estimated from graphical analysis of EadieHofstee plots. These values were then used as first estimates for MK Model, an extended least squares modelling programme [21]. Also, the $K_{m}$ values for formation of 5-O-desmethylomeprazole ( $\mathrm{H} 215 / 02)$ and metabolite $\mathrm{X}$ were estimated using peak height ratios as an index of reaction velocity. However, as the assay could not be fully validated for quantitation of these metabolites, these parameter values should be regarded as estimates only.

\section{Correlation experiments}

Formation rates of omeprazole sulphone and hydroxyomeprazole were also measured using microsomes from 14 kidney donor livers (KDL) from the Basel liver bank. S- and R-mephenytoin hydroxylase activities have previously been measured in these livers [17]. The omeprazole concentration used for incubation in these experiments and in the following correlation and inhibition experiments was $5 \mu \mathrm{M}$ to assess mainly the high affinity activities (see Results).

Eighteen different livers from the Flinders Medical Centre liver bank (H-livers) were also tested for activity 
as regards formation of different omeprazole metabolites. These activities were then correlated with activities towards the metabolism of other substrates using these livers. The data for the CYP2C9/10 activity, tolbutamide methylhydroxylation, the CYP3A activity, benzo[a] pyrene metabolism and the CYP2E1 activity, chlorzoxazone 6-hydroxylation, have been published previously $[16,22,23]$. The CYP1A2 activity, phenacetin $O$ deethylation (high affinity component), was determined by the method of Tassaneeyakul et al. [24]. Correlations were also tested with regard to CYP2E1 and CYP3A protein contents estimated by Western blot techniques previously described [16, 23]. Duplicate sample determinations were used in all correlation experiments.

\section{Inhibition experiments}

The effects of inhibitors or substrates (and therefore competitive inhibitors) selective for various CYP isoforms on omeprazole metabolic pathways were studied. The isoform selective inhibitors or alternative substrates were $\alpha$-naphthoflavone (CYP1A inhibition at low concentrations and normally CYP3A activation at higher concentrations; [16]): furafylline (CYP1A2; [25]): coumarin (CYP2A6; [26, 27]): sulphaphenazole (CYP2C9/10; [28]): R, S-mephenytoin (S-mephenytoin hydroxylase; [29]): quinidine (CYP2D6; [30, 31]): diethyldithiocarbamate (CYP2E1; [32]): and troleandomycin (CYP3A; [33]). The putative inhibitors were studied at two concentrations chosen to be selective for the respective CYP isoforms on the basis of published $K_{\mathrm{i}}$ or $K_{m}$ values. Except for diethyldithiocarbamate, which was dissolved in water, inhibitors were dissolved in DMSO with a volume of $5 \mu$ ladded to the incubation mixture (final concentration $0.5 \%$ DMSO). This concentration of DMSO inhibited the formation of omeprazole sulphone, hydroxyomeprazole, 5-O-desmethylomeprazole ( $\mathrm{H} \mathrm{215/02)}$ and metabolite $\mathrm{X}$ by $16 \%, 17 \%, 9 \%$ and $41 \%$, respectively. At $1.0 \%$ and $1.5 \%$ concentrations of DMSO, sulphone formation was inhibited by $27 \%$ and $70 \%$, respectively, and hydroxyomeprazole formation by $18 \%$ and $31 \%$, respectively. In all cases, inhibited activities were compared with activities of control incubations containing $5 \mu \mathrm{l}(0.5 \%)$ DMSO or $5 \mu \mathrm{l}$ water as appropriate. Troleandomycin was preincubated with microsomes and NADPH generating system for $10 \mathrm{~min}$ before the reaction was started by addition of the substrate omeprazole, since a metabolite formed during troleandomycin incubation exerts the inhibitory effect on CYP3A enzymes [33]. Otherwise, there was no preincubation with inhibitor and incubations were started by adding NADPH generating system. Three different livers - H8, H9 and $\mathrm{H} 10$ - were investigated for all inhibitors and duplicate samples were used in all inhibition experiments.

\section{Analysis of results}

All results are presented as mean \pm s.d. Likelihood or significance of correlations in the correlation experiments was tested by 'Spearman Rank Correlation', and was corrected for ties. The high affinity $K_{m}$ values for the four metabolites were compared by ANOVA with comparison of the means by the Student-Newman-Keuls test. Values of $P<0.05$ were regarded as statistically significant.

\section{Results}

Microsomes from all livers studied converted omeprazole to omeprazole sulphone, hydroxyomeprazole and to two other minor metabolites. As discussed previously, one of these metabolites (retention time $11 \mathrm{~min}$ ) was tentatively identified as the compound $O$-demethylated at the 5 position on the benzimidazole moiety (5- $O$-desmethylomeprazole or H 215/02). The other compound chromatographed with a retention time of $3.8 \mathrm{~min}$ (metabolite X) and did not correspond to any of the omeprazole derivatives available as synthetic standards (hydroxysulphone, and the sulphide from each of hydroxyomeprazole and 5-O-desmethylomeprazole). None of the four metabolites was produced in the absence of the NADPH generating system. Incubation of hydroxyomeprazole and omeprazole sulphone with microsomes and NADPH generating system produced in both cases a major peak with a retention time $(9 \mathrm{~min})$ corresponding to that of the synthetic hydroxysulphone.

Figure 2 shows representative Eadie-Hofstee plots for the formation of hydroxyomeprazole and omeprazole

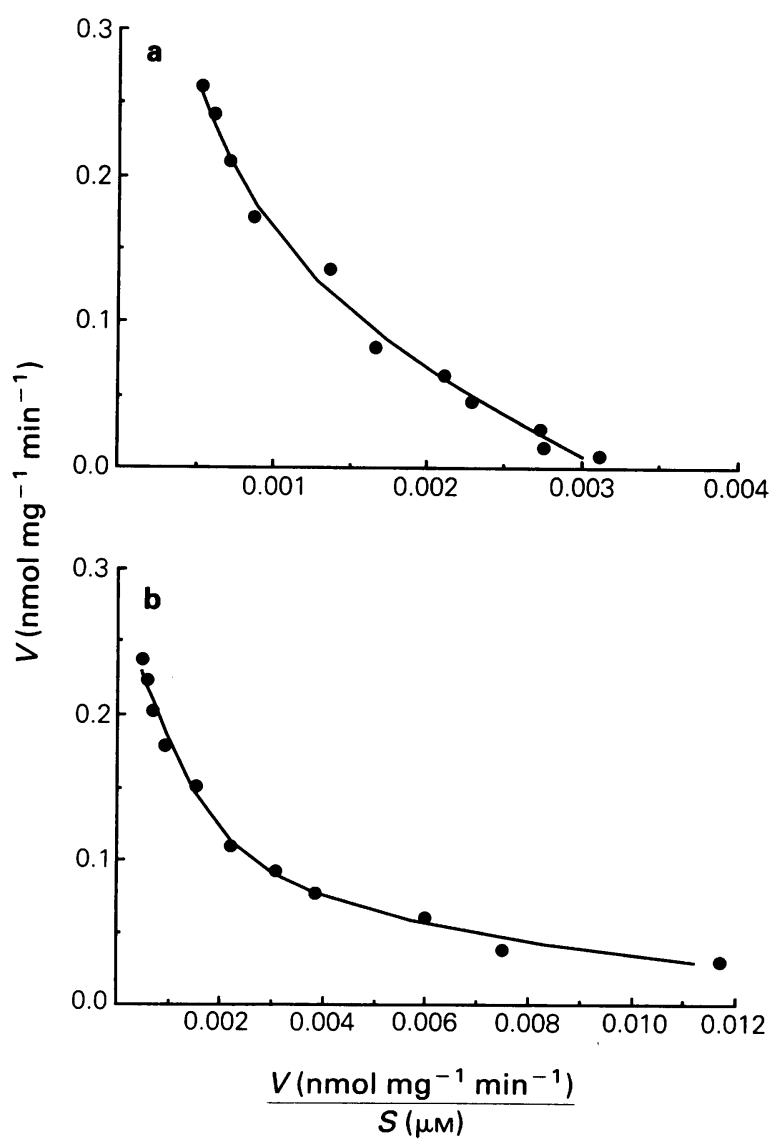

Figure 2 Representative Eadie-Hofstee plots for formation of a) omeprazole sulphone and b) hydroxyomeprazole by microsomes from liver H8. Points are experimentally determined values while solid lines are the computer generated curves of best fit. 
sulphone. Plots for both metabolites were non-linear for all four livers studied, indicating the involvement of multiple CYP isoforms in these reactions. In each case, the data were able to be fitted to the Michaelis-Menten expression for a two-enzyme system. The derived $K_{m}$ and $V_{\max }$ values are shown in Table 1 . For 5-Odesmethylomeprazole sufficient synthetic standard was not available for formal quantitation. However, $K_{m}$ values for both 5-O-desmethylomeprazole and metabolite $\mathrm{X}$ were derived using peak height ratio as an index of reaction velocity. The data were fitted with a two enzyme model and the derived $K_{m}$ values are shown in Table 2. The high affinity $K_{m}$ values for hydroxyomeprazole and 5-O-desmethylomeprazole were not significantly different, but in each case were significantly different from those for the sulphone and metabolite X. The high affinity $K_{m}$ value for the sulphone was not significantly different from that for metabolite $\mathrm{X}(F=11.68, P=0.0007$; least significant difference of the means $=20.43$ ).

The low affinity $K_{m}$ values for the four pathways ranged from $139 \pm 56 \mu \mathrm{M}$ for 5-O-desmethylomeprazole formation to $484 \pm 190 \mu \mathrm{M}$ for sulphone formation.

The Michaelis-Menten expression for a two enzyme system was used with the mean $K_{m}$ and $V_{\max }$ values in Table 1 to derive an omeprazole substrate concentration $(5 \mu \mathrm{M})$ that would result in approximately $80 \%$ contribution of the high affinity activity to total reaction velocity in further experiments. However, the individually calculated contributions were $82 \%, 78 \%$ and $68 \%(\mathrm{H} 8$, $\mathrm{H} 9$ and $\mathrm{H} 10$ ) for the formation of omeprazole sulphone, and $82 \%, 94 \%$ and $57 \%$ for the formation of hydroxyomeprazole. For metabolite $\mathrm{X}$ the corresponding figures were $82 \%, 71 \%$ and $75 \%$, and for $5-O$-desmethylomeprazole they were $78 \%, 81 \%$ and $8 \%$. Given the very low contribution of the high affinity form to the formation of 5-O-desmethylomeprazole in liver $\mathrm{H} 10$, inhibition data for this pathway in this liver were not analysed.

\section{Correlation experiments}

The only significant correlations between the omeprazole metabolic pathways were between sulphone formation and formation of metabolite $\mathrm{X}(r=0.95)$ and between the hydroxyomeprazole formation and formation of metabolite $\mathrm{X}(r=0.53)$ (Table 3$)$. There were also weak correlations, however not significant, between the hydroxyomeprazole formation and formation of 5-O- desmethylomeprazole ( $r=0.44)$ and between hydroxyomeprazole and sulphone formations $(r=0.42)$ (Table 3 ). None of the four omeprazole metabolic pathways (formation of sulphone, hydroxyomeprazole, 5-Odesmethylomeprazole and metabolite $\mathrm{X}$ ) was significantly correlated with high affinity phenacetin $O$-deethylase (CYP1A2), tolbutamide methylhydroxylase (CYP2C9/ 10), or chlorzoxazone 6-hydroxylase (CYP2E1) (Table 3 ). Consistent with this latter observation, none of the omeprazole activities was correlated significantly with CYP2E1 protein content (Table 3).

Omeprazole sulphone formation was strongly correlated with the CYP3A mediated benzo[a]pyrene metabolism and with CYP3A protein content (Table 3 ). Hydroxyomeprazole formation was strongly correlated with S-mephenytoin hydroxylase activity (Table 3). Formation of metabolite $\mathrm{X}$ similarly correlated with both benzo[a]pyrene metabolism and with CYP3A protein content.

There were significant but weaker correlations between hydroxyomeprazole formation and both benzo[a]pyrene metabolism and CYP3A protein content and between sulphone formation and R-mephenytoin hydroxylase activity.

\section{Inhibition experiments}

The effects of various inhibitors/substrates on the formation of omeprazole metabolites are shown in Figures 3 and 4. Inhibitors selective for CYP1A2 ( $\alpha$-naphthoflavone, furafylline), CYP2A6 (coumarin), CYP2C9/10 (sulphaphenazole) and CYP2E1 (diethyldithiocarbamate) had essentially no effect on any of the omeprazole metabolic pathways. $\mathrm{R}$, S-mephenytoin inhibited

Table 2 Computer derived apparent $K_{m} \mathrm{~s}$ for formation of 5-O-desmethylomeprazole (H 215/02) and metabolite X in human liver microsomes from four livers

\begin{tabular}{lcccc}
\hline Liver & \multicolumn{2}{c}{ H215/02 formation } & \multicolumn{2}{c}{ Metabolite X formation } \\
number & $\mathrm{K}_{\mathrm{m} 1}$ & $\mathrm{~K}_{\mathrm{m} 2}$ & $\mathrm{~K}_{\mathrm{m} 1}$ & $\mathrm{~K}_{\mathrm{m} 2}$ \\
\hline H8 & 2.9 & 174 & 42 & 477 \\
H9 & 9.1 & 190 & 70 & 243 \\
H10 & 9.3 & 64 & 35 & 238 \\
H15 & 33 & 129 & 60 & 326 \\
Mean & 13.6 & 139 & 52 & 321 \\
土 s.d. & 13.3 & 56 & 16 & 112 \\
\hline
\end{tabular}

Note: $K_{m}$ expressed as $\mu \mathrm{M}$

Table 1 Computer derived Michaelis-Menten parameters for formation of omeprazole sulphone and hydroxyomeprazole in human liver microsomes from four livers

\begin{tabular}{lcccccccc}
\hline Liver & \multicolumn{3}{c}{ Sulphone formation } & \multicolumn{3}{c}{ Hydroxyomeprazole formation } \\
number & $\mathrm{K}_{\mathrm{m} 1}$ & $\mathrm{~K}_{\mathrm{m} 2}$ & $\mathrm{~V}_{\max 1}$ & $\mathrm{~V}_{\max 2}$ & $\mathrm{~K}_{\mathrm{m} 1}$ & $\mathrm{~K}_{\mathrm{m} 2}$ & $\mathrm{~V}_{\max 1}$ & $\mathrm{~V}_{\max 2}$ \\
\hline H8 & 45 & 692 & 0.12 & 0.36 & 3.4 & 139 & 0.057 & 0.22 \\
H9 & 52 & 579 & 0.16 & 0.45 & 9.9 & 354 & 0.19 & 0.32 \\
H10 & 30 & 264 & 0.10 & 0.36 & 5.2 & 81 & 0.038 & 0.24 \\
H15 & 67 & 400 & 0.36 & 0.41 & 16 & 126 & 0.11 & 0.38 \\
Mean & 49 & 484 & 0.19 & 0.40 & 8.6 & 175 & 0.099 & 0.29 \\
I s.d. & 15 & 190 & 0.12 & 0.04 & 5.6 & 122 & 0.068 & 0.07 \\
\hline
\end{tabular}

Note: $K_{m}$ expressed as $\mu \mathrm{M}$ and $V_{\max }$ expressed as $\mathrm{nmol} \mathrm{mg}^{-1} \mathrm{~min}^{-1}$. 
Table 3 Spearman rank correlations ( $r$ ) between the formation velocity of omeprazole metabolites and specific CYP activities or isoform contents

\begin{tabular}{|c|c|c|c|c|c|}
\hline Activity or isoform content & Isoform & $\begin{array}{c}\text { Omeprazole } \\
\text { sulphone }\end{array}$ & $\begin{array}{l}\text { Hydroxy- } \\
\text { omeprazole }\end{array}$ & H 215/02 & Metabolite X \\
\hline $\begin{array}{l}\text { Flinders liver bank } \mathrm{n}=18^{\mathrm{a})} \\
\text { Omeprazole sulphone }\end{array}$ & - & - & 0.42 & 0.21 & $0.95^{*}$ \\
\hline Hydroxyomeprazole & - & - & - & 0.44 & $0.53 *$ \\
\hline $\mathrm{H} 215 / 02^{\mathrm{b})}$ & - & - & - & - & 0.25 \\
\hline $\begin{array}{l}\text { Phenacetin } O \text {-deethylase } \\
\text { (high affinity) }\end{array}$ & $1 \mathrm{~A} 2$ & -0.10 & 0.39 & 0.02 & -0.06 \\
\hline Tolbutamide hydroxylase & $2 \mathrm{C} 9 / 10$ & -0.09 & 0.12 & 0.09 & 0.05 \\
\hline Chlorzoxazone hydroxylase & $2 \mathrm{E} 1$ & -0.14 & -0.18 & -0.10 & -0.24 \\
\hline Benzo[a]pyrene metabolism & $3 \mathrm{~A}$ & $0.80^{*}$ & $0.64 *$ & -0.18 & $0.90^{*}$ \\
\hline CYP2E1 protein & $2 \mathrm{E} 1$ & -0.23 & 0.01 & 0.10 & -0.30 \\
\hline CYP3A protein & $3 \mathrm{~A}$ & $0.89^{*}$ & $0.69^{*}$ & -0.22 & $0.93 *$ \\
\hline $\begin{array}{l}\text { Basel liver bank } \mathrm{n}=14^{\mathrm{c})} \\
\text { S-mephenytoin hydroxylase }\end{array}$ & $2 \mathrm{C} 18$ & -0.38 & $0.75^{*}$ & - & - \\
\hline R-mephenytoin hydroxylase & $?$ & $0.55^{*}$ & 0.47 & - & - \\
\hline
\end{tabular}

a) for $r>0.468, P<0.05$.

b) 5 - $O$-desmethylomeprazole.

c) for $r>0.532, P<0.05$.

$* P<0.05$.

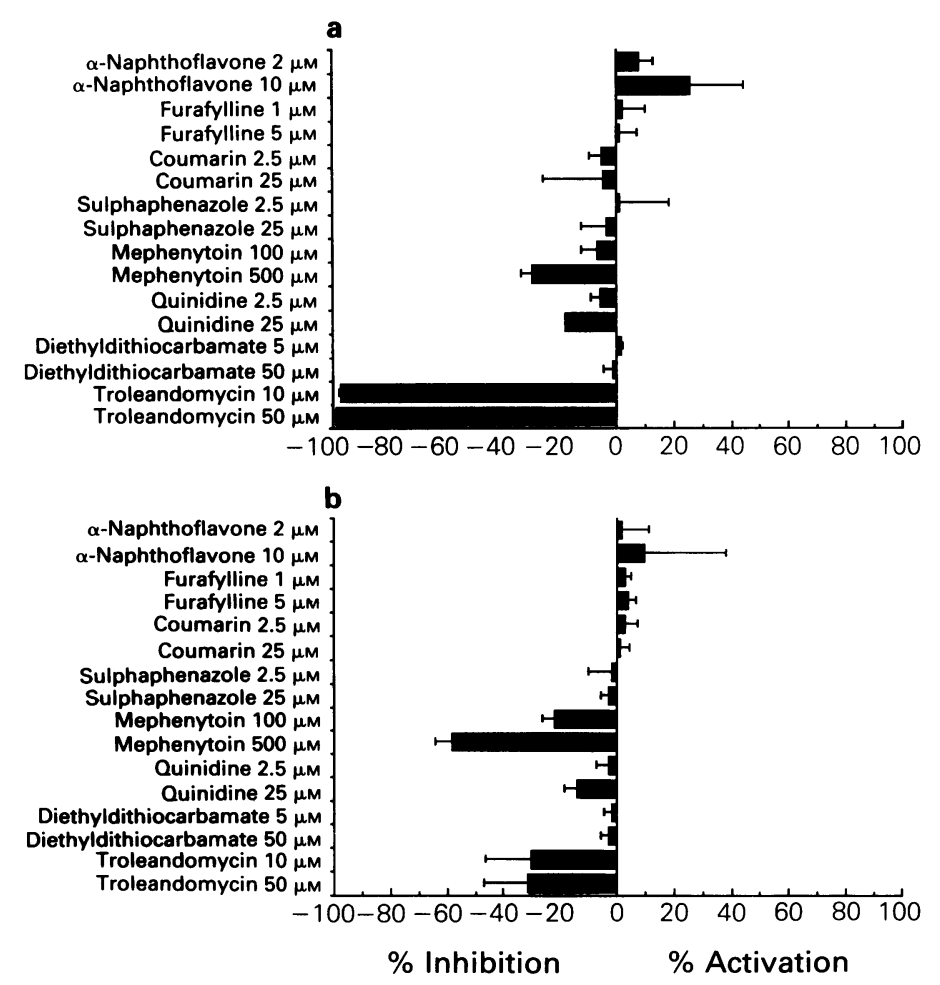

Figure 3 Effects of various specific CYP inhibitors and/or substrates on the formation of a) omeprazole sulphone and b) hydroxyomeprazole in human liver microsomes. Each bar represents the mean \pm s.d. of three different livers (H8, H9 and H10) and each liver was studied in duplicate samples.

hydroxyomeprazole formation by $58 \%$ at the higher inhibitor concentration, and also inhibited 5-O-desmethylomeprazole formation by $57 \%$. The higher concentration of mephenytoin had weaker inhibitory effects on sulphone formation ( $30 \%$ inhibition) and on metabolite X formation ( $34 \%$ inhibition). Troleando- mycin (CYP3A) essentially abolished sulphone and metabolite $X$ formation ( $>90 \%$ inhibition), but also exerted a weak inhibitory effect on hydroxyomeprazole formation ( $30 \%$ inhibition). Consistent with this, $\alpha$ naphthoflavone $10 \mu \mathrm{M}$ (which normally activates isoforms of the CYP3A subfamily) activated sulphone 

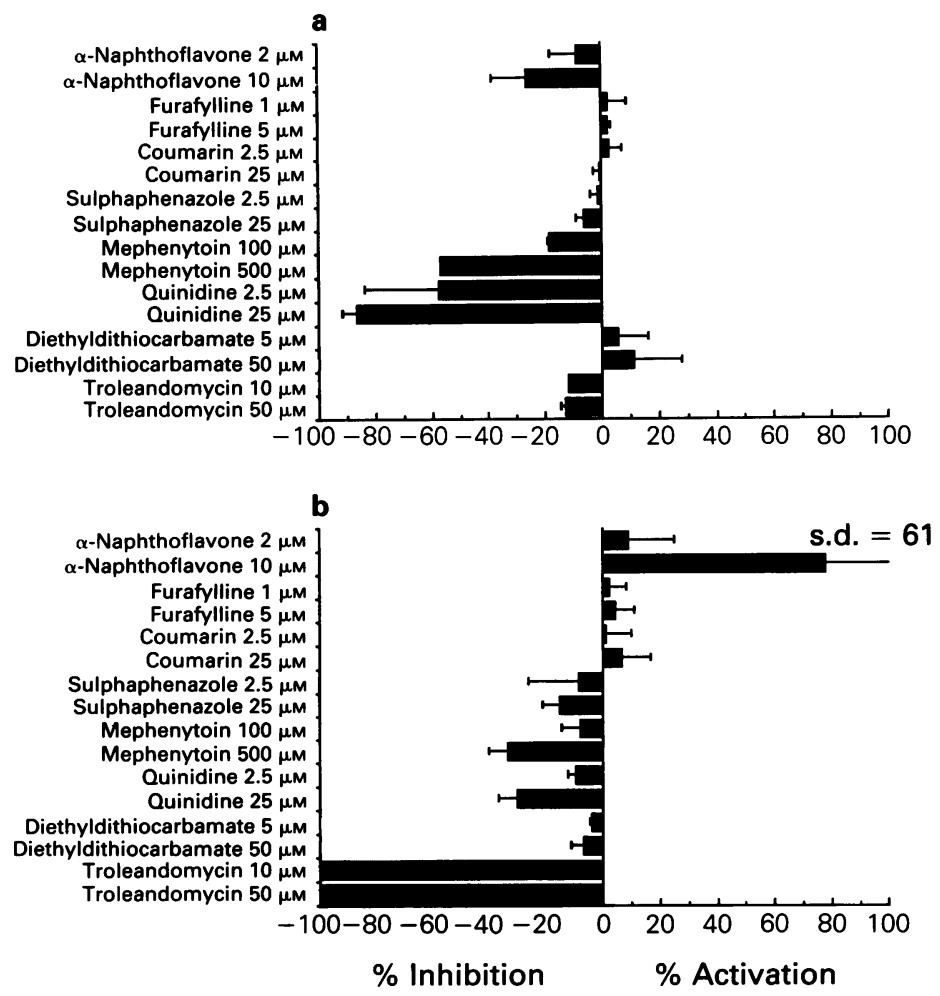

Figure 4 Effects of various specific CYP inhibitors and/or substrates on the formation of a) 5- $O$-desmethylomeprazole (H 215/ $02)$ and b) metabolite $X$ in human liver microsomes. Each bar represents the mean \pm s.d. of two different livers (H8 and H9) for 5-O-desmethylomeprazole and of three different livers $(\mathrm{H} 8, \mathrm{H} 9$ and $\mathrm{H} 10)$ for metabolite $\mathrm{X}$. Each liver was studied in duplicate samples.

formation by $26 \%$ and metabolite $X$ formation by $78 \%$ but did not activate formation of 5-O-desmethylomeprazole or hydroxyomeprazole. The use of higher concentrations of $\alpha$-naphthoflavone to demonstrate further the activation of the formation of omeprazole sulphone was not possible since there were potential interfering peaks which precluded quantitation of this metabolite. Quinidine (CYP2D6) at the higher concentration had a substantial inhibitory effect on 5-O-desmethylomeprazole formation ( $86 \%$ ) but also had minor inhibitory effects on the formation of the other omeprazole metabolites.

\section{Discussion}

On the basis of the results of the present studies and previously reported in vivo findings, a proposed scheme for omeprazole metabolism in humans is presented in Figure 1.

The major metabolites produced from omeprazole by microsomes from thirty-two human livers were omeprazole sulphone and hydroxyomeprazole (Figure 1). This is in agreement with these two compounds being the major metabolites detected in vivo in human plasma [7]. In vivo, the sulphone metabolite is apparently completely further biotransformed as it does not appear in urine to any appreciable extent [10]. The analytical method used here has been validated fully for quantitation of these two compounds [20].
Two further peaks were found in the chromatograms after incubation of omeprazole with human liver microsomes. One of these was tentatively identified by comparison with authentic synthetic standards as 5-Odesmethylomeprazole (H 215/02; demethylated in the benzimidazole moiety) [Figure 1], while the other still remains unidentified (metabolite X). Although sufficient analytical standard was not available to validate fully the quantitation of 5-O-desmethylomeprazole, peak height ratios for this metabolite and for metabolite $\mathrm{X}$ could be used to estimate their relative rates of formation from omeprazole by microsomes from different livers, for both inhibition studies and to estimate kinetic parameters. Omeprazole pyridone seemed to be formed in very small amounts only, and was therefore not evaluated in this work. Moreover, omeprazole sulphide was formed during the preparation procedures and could therefore not be evaluated as a metabolite.

After incubation of human liver microsomes with omeprazole, hydroxyomeprazole or omeprazole sulphone, no peaks were seen corresponding to hydroxyomeprazole-sulphide $(\mathrm{H} 195 / 69)$ or 5 -O-desmethylomeprazole-sulphide (H 182/68) indicating that these are unlikely to be significant, hepatically formed metabolites of omeprazole in vivo. Incubation of omeprazole sulphone and hydroxyomeprazole with human liver microsomes gave, in each case, a major peak corresponding to the hydroxysulphone (H 195/77; Figure 1) indicating that this is likely to be an important in vivo pathway for secondary biotransformation of these primary metabolites. In vivo, hydroxyomeprazole 
is also, at least in part, converted to carboxyomeprazole (H 193/48; Figure 1) which is found as a major metabolite, together with hydroxyomeprazole, in urine [10]. This pathway is likely to be catalyzed by alcohol and aldehyde dehydrogenases which are cytosolic enzymes, the activity of which would not have been detected in the current work using microsomal systems.

The kinetics of sulphone formation were biphasic suggesting that at least two CYP isoforms can catalyse sulphone formation. Only the high affinity form is likely to be involved at concentrations achieved in vivo, so correlation and inhibition studies were performed at low omeprazole concentrations where the high affinity activity predominated. Similar biphasic kinetics were observed for formation of hydroxyomeprazole, 5-Odesmethylomeprazole and metabolite $\mathrm{X}$. The high affinity $K_{m}$ values for the four pathways indicated that the formation of hydroxyomeprazole and 5-O-desmethylomeprazole might be performed by the same CYP isoform, and the formation of the sulphone and metabolite $\mathrm{X}$ seemed to be dependent on the activity of the same CYP isoform, however different from that for hydroxyomeprazole and 5-O-desmethylomeprazole.

The rate of sulphone formation with human liver microsomes was correlated significantly with benzo[a]pyrene metabolism (CYP3A) and with CYP3A protein content but not with phenacetin $O$-deethylation (CYP1A2) tolbutamide hydroxylation (CYP2C9/10), S-mephenytoin hydroxylation (possibly CYP2C18), chlorzoxazone hydroxylation (CYP2E1), or with CYP2E1 protein content. Consistent with this, sulphone formation was potently inhibited by the CYP3A selective inhibitor troleandomycin and activated by $\alpha$-naphthoflavone. Selective inhibitors of CYP1A2 ( $\alpha$-naphthoflavone, furafylline), CYP2A6 (coumarin), CYP2C9/10 (sulphaphenazole) and CYP2E1 (diethyldithiocarbamate) had no effect on microsomal omeprazole sulphone formation excluding a role for these CYP isoforms in the formation of this metabolite. The marginal inhibition obtained by the high concentration of quinidine is probably not an effect on CYP2D6 but is rather a result of non-specific inhibition of CYP3A since quinidine is a known substrate for CYP3A [30]. R, S-mephenytoin at a concentration of $500 \mu \mathrm{M}$ caused some inhibition $(\sim 30 \%)$ of sulphone formation. This could be due to a minor role of the polymorphic S-mephenytoin hydroxylase in sulphone formation or to non-selective inhibition of the CYP3A subfamily by R, S-mephenytoin. Overall the data are fully consistent with a predominant role of the CYP3A subfamily in omeprazole sulphone formation. This is in agreement with in vivo data showing that sulphone formation is not linked to S-mephenytoin hydroxylase activity $[7,13,14]$.

By contrast with sulphone formation, microsomal omeprazole hydroxylation was strongly correlated with $\mathrm{S}$-mephenytoin hydroxylation. As with sulphone formation, there was no correlation with activities or protein content representing CYP1A2, CYP2C9/10 or CYP2E1. There was also a significant correlation with benzo[a]pyrene metabolism and CYP3A protein content indicating that the CYP3A subfamily may mediate part of the hydroxylation activity. In agreement with the correlation experiments, R, S-mephenytoin caused substantial inhibition of the hydroxylation reaction while troleandomycin (CYP3A) was only a weak inhibitor of this reaction. $\alpha$-Naphthoflavone activated hydroxyomeprazole formation with microsomes from one of three livers only (H10). These microsomes also exhibited the greatest inhibition of hydroxyomeprazole formation by troleandomycin in the inhibition experiments. Since CYP3A activity might be involved in the low affinity component of hydroxyomeprazole formation, the indication of a higher CYP3A contribution to the formation of hydroxyomeprazole in this liver may be explained by the relatively high contribution $(43 \%)$ of the low affinity component in this liver compared with the others $(18 \%$ and $6 \%)$. Nevertheless, the in vitro studies indicate a dominant role of the S-mephenytoin hydroxylase isoform in omeprazole hydroxylation in agreement with in vivo data showing that this biotransformation pathway is strongly linked with the S-mephenytoin polymorphism. The in vitro data suggest further that isoforms of the CYP3A subfamily may possibly also be involved in omeprazole hydroxylation in vivo, particularly if induction of the CYP3A isoforms has occurred.

The two minor metabolites, one tentatively identified as 5-O-desmethylomeprazole (the product of demethylation on the benzimidazole moiety) and the other unidentified as yet (metabolite $\mathrm{X}$ ), were quantitated by peak height ratios. The formation of 5-O-desmethylomeprazole as measured by peak height was weakly, but not significantly, correlated with that of hydroxyomeprazole but not with any of the other activities or protein contents studied. Formation of 5-O-desmethylomeprazole was significantly inhibited by $R, S-$ mephenytoin and also by quinidine. These data suggest that the formation of 5-O-desmethylomeprazole could be mediated by $\mathrm{S}$-mephenytoin hydroxylase and by CYP2D6. Formation of the other minor metabolite, metabolite $\mathrm{X}$, behaved in a very similar manner to sulphone formation. It was highly correlated with omeprazole sulphone formation, benzo[a]pyrene metabolism and CYP3A protein content, but not with any of the other activities or protein contents studied. It was inhibited completely by low concentrations of troleandomycin and weakly by $\mathrm{R}$, S-mephenytoin and quinidine but not substantially affected by inhibitors selective for other isoforms. It was strongly activated by $\alpha$-naphthoflavone. Taken together, these results indicate a major role for isoforms of the CYP3A subfamily in formation of this unknown metabolite.

The in vitro studies reported here show excellent concordance with in vivo results and demonstrate the potential for in vitro metabolism studies to predict genetic, environmental and drug interaction effects on drug metabolism in vivo. The major in vivo metabolic pathways (sulphone formation and hydroxylation) could be identified from the in vitro data and minor metabolic pathways have been detected. Likely secondary biotransformations of the major primary metabolites have been identified. Correlation and inhibition studies indicate that the polymorphic S-mephenytoin hydroxylase is dominant in hydroxyomeprazole formation whereas CYP3A isoforms are dominant in sulphone and metabolite $\mathrm{X}$ formation.

Estimates of relative intrinsic clearance, based on $V_{\max } / K_{m}$ calculations, indicate that at low concentrations, 
i.e. comparable with those obtained in a clinical situation, hydroxyomeprazole formation is four times greater than sulphone formation. The formation of hydroxyomeprazole is shown here to be mediated by S-mephenytoin hydroxylase which is consistent with the major defect in omeprazole plasma clearance observed in poor S-mephenytoin hydroxylators in vivo [11-14]. The in vitro data presented here further suggest that agents inducing (e.g. dexamethasone) or inhibiting (e.g. erythromycin) the CYP3A isoforms would alter omeprazole

\section{References}

1 Fellenius E, Berglindh T, Sachs G, Olbe L, Elander B, Sjöstrand S-E, Wallmark B. Substituted benzimidazoles inhibit gastric acid secretion by blocking $\left(\mathrm{H}^{+}+\mathrm{K}^{+}\right)$ ATPase. Nature 1981; 290: 159-161.

2 Lind T, Cederberg C, Ekenved G, Haglund U, Olbe L. Effect of omeprazole - a gastric proton pump inhibitoron pentagastrin stimulated acid secretion in man. Gut 1983; 24: 270-276.

3 Wallmark B, Lorentzon P, Larsson H. The mechanism of action of omeprazole - a survey of its inhibitory actions in vitro. Scand J Gastroenterol 1985; 20: (Suppl. 108), 37-51.

4 Bardhan KD, Bianchi-Porro G, Bose K, Daly M, Hinchliffe RF, Jonsson E, Lazzaroni M, Naesdal J, Rikner L, Walan A. A comparison of two different doses of omeprazole versus ranitidine in treatment of duodenal ulcer. $J$ clin Gastroenterol 1986; 8: 408-413.

5 Klinkenberg-Knol EC, Jansen JMBJ, Festen HPM, Meuwissen S-GM, Lamers CBHW. Double-blind multicentre comparison of omeprazole and ranitidine in the treatment of reflux oesophagitis. Lancet 1987; i: 349-351.

6 Walan A, Bader JP, Classen M, Lamers CBHW, Piper DW, Rutgersson K, Eriksson S. Effect of omeprazole and ranitidine on ulcer healing and relapse rates in patients with benign gastric ulcer. New Engl J Med 1989; 320: 6975.

7 Andersson T. Pharmacokinetics of omeprazole in man: with special reference to single and repeated administration, drug interactions and polymorphic metabolism. $\mathrm{PhD}$. Thesis, University of Göteborg, Sweden.

8 Regårdh CG, Andersson T, Lagerström PO, Lundborg P, Skånberg $\mathrm{I}$. The pharmacokinetics of omeprazole in humans - a study of single intravenous and oral doses. Ther Drug Monit 1990; 12: 163-172.

9 Lind T, Andersson T, Skånberg I, Olbe L. Biliary excretion of intravenous $\left[{ }^{14} \mathrm{C}\right]$ omeprazole in humans. Clin Pharmac Ther 1987; 42: 504-508.

10 Renberg L, Simonsson R, Hoffman KJ. Identification of two main urinary metabolites of $\left[{ }^{14} \mathrm{C}\right]$ omeprazole in humans. Drug Metab Dispos 1989; 17: 69-76.

11 Andersson T, Cederberg C, Edvardsson G, Heggelund A, Lundborg P. Effect of omeprazole treatment on diazepam plasma levels in slow versus normal rapid metabolizers of omeprazole. Clin Pharmac Ther 1990; 47: 79-85.

12 Andersson, T, Regårdh CG, Dahl-Puustinen ML, Bertilsson L. Slow omeprazole metabolizers are also poor S-mephenytoin hydroxylators. Ther Drug Monit 1990; 12: 415-416.

13 Andersson T, Regårdh C-G, Lou Y-C, Zhang Y, Dahl M-L, Bertilsson L. Polymorphic hydroxylation of Smephenytoin and omeprazole metabolism in Caucasian and Chinese subjects. Pharmacogenetics 1992; 2: 25-31.

14 Sohn DR, Kobayashi K, Chiba K, Lee KH, Shin SG, Ishizaki T. Disposition kinetics and metabolism of sulphone formation in vivo. These interactions would not have major effects on total plasma omeprazole clearance, however, as the in vitro results suggest that this pathway is relatively less important than hydroxyomeprazole formation.

The authors gratefully acknowledge Professor M. McManus for supplying data on benzo(a)pyrene metabolism and CYP3A content. The studies were financially supported by Australian National Health and Medical Research Council and the Australian Tobacco Research Foundation.

omeprazole in extensive and poor metabolizers of Smephenytoin 4'-hydroxylation recruited from an oriental population. J Pharmac exp Ther 1992; 262: 1195-1202.

15 Romkes M, Faletto MB, Blaisdell JA, Raucy JL, Goldstein JA. Cloning and expression of complementary DNAs for multiple members of the human cytochrome P450IIC subfamily. Biochemistry 1991; 30: 3427-3455.

16 McManus ME, Burgess WM, Veronese ME, Huggett A, Quattrochi LC, Tukey RH. Metabolism of 2-acetylaminofluorene and benzo(a)pyrene and activation of food-derived heterocyclic amine mutagens by human cytochromes $\mathrm{P} 450$. Cancer Res 1990; 50: 3367-3376.

17 Meier UT, Dayer P, Male PJ, Kronbach T, Meyer UA. Mephenytoin hydroxylation polymorphism: characterization of the enzymatic deficiency in liver microsomes of poor metabolizers phenotyped in vivo. Clin Pharmac Ther 1985; 38: 488-494.

18 Robson RA, Matthews AP, Miners JO, McManus ME, Meyer UA, Hall PM, Birkett DJ. Characterisation of theophylline metabolism by human liver microsomes. $\mathrm{Br} \mathrm{J}$ clin Pharmac 1987; 24: 293-300.

19 Lowry OH, Rosebrough NJ, Farr AL, Randall RJ. Protein measurement with the Folin phenol reagent. J biol Chem 1951; 193: 265-275.

20 Andersson T, Lagerström PO, Miners JO, Veronese ME, Weidolf L, Birkett DJ. High performance liquid chromatographic assay for human liver microsomal omeprazole metabolism. J Chromatogr 1993; (in press).

21 Holford NHG. Mk Model: a modelling tool for microcomputers. Pharmacokinetic evaluation and comparison with standard computer programmes. Clin exp Pharmac Physiol 1985; Suppl., 9: 95.

22 Doecke CJ, Veronese ME, Pond SM, Miners JO, Birkett DJ, Sansom LN, McManus ME. Relationship between phenytoin and tolbutamide hydroxylations in human liver microsomes. Br J clin Pharmac 1991; 31: 125-130.

23 Tassaneeyakul W, Veronese ME, Birkett DJ, Gonzalez FJ, Miners JO. Validation of 4-nitrophenol as an in vitro substrate probe for human CYP2E1 using cDNAexpression and microsomal kinetic techniques. Biochem Pharmac 1993; (in press).

24 Tassaneeyakul W, Birkett DJ, Veronese ME, McManus ME, Tukey RH, Quattrochi LC, Gelboin HV, Miners JO. Specificity of substrate and inhibitor probes for human cytochromes P450 1A1 and 1A2.J Pharmac exp Ther 1993; 265: 401-407.

25 Sesardic D, Boobis AR, Murray BP, Murray S, Segura J, de-la-Torre R, Davies DS. Furafylline is a potent and selective inhibitor of cytochrome P4501A2 in man. Br J clin Pharmac 1990; 29: 651-663.

26 Yamano S, Tatsuno J, Gonzalez FJ. The CYP2A3 gene product catalyzes coumarin 7-hydroxylation in human liver microsomes. Biochemistry 1990; 29: 1322-1329. 
27 Yun $\mathrm{CH}$, Shimada T, Guengerich FP. Purification and characterization of human liver microsomal cytochrome P450 2A6. Mol Pharmac 1991; 40: 679-685.

28 Veronese ME, Doecke CJ, Mackenzie PI, McManus ME, Miners JO, Rees DL, Gasser R, Meyer UA, Birkett DJ. Site-directed mutation studies of human liver cytochrome P450 isoenzymes in the CYP2C subfamily. Biochem J 1993; 289: 533-538.

29 Küpfer A, Preisig R. Pharmacogenetics of mephenytoin: a new drug hydroxylation polymorphism in man. Eur J clin Pharmac 1984; 26: 753-759.

30 Guengerich FP, Müller-Enoch D, Blair IA. Oxidation of quinidine by human liver cytochrome P-450. Mol Pharmac 1986; 30: 287-295.

31 Inaba T, Jurima M, Mahon WA, Kalow M. In vitro inhibi- tion studies of two isozymes of human liver cytochrome P450. Mephenytoin p-hydroxylase and sparteine monooxygenase. Drug Metab Dispos 1985; 13: 443-448.

32 Guengerich FP, Kim DH, Iwasaki M. Role of human cytochrome P-450IIE1 in the oxidation of many low molecular weight cancer suspects. Chem Res Toxicol 1991; 4: 168-179.

33 Pessayre D, Tinel M, Larrey D, Cobert B, Funck-Brentano C, Babany G. Inactivation of cytochrome P-450 by a troleandomycin metabolite. Protective role of glutathione. J Pharmac exp Ther 1983; 224: 685-691.

(Received 24 May 1993, accepted 5 August 1993) 